\title{
논문 2012-07-22
}

\section{리프팅 기반의 고속 정수 웨이블릿 변환의 효율적인 구현 구조
(An Efficient Implementation Architecture for Lifting Based High Speed Integer Wavelet Transform)

\author{
김 석 준, 장 영 조* \\ (Suc June Kim, Young Jo Jang)
}

\begin{abstract}
In this paper, we propose an efficient architecture for 2D IWT using an existing 1D IWT. Lifting based IWT is the architecture of which a multiplier is replaced by adders and shift registers. The structure is relatively simple and modular. The proposed architecture to process an image size with $256 \times 256$ pixels consists of 16 adders, 8 shift registers, and some memories. By processing two rows at the same time, 2D sub-band coefficients can be calculated immediately after 1D sub-band coefficients have been processed. The architecture is designed so that each image can be inputted consecutively. The number of adders and shift registers is increased by twice comparing the existing architecture, but the memory size and the execution time are decreased by half. The proposed architecture is implemented using Verilog-HDL and simulated using iSim. It is synthesized and demonstrated at ISE for xc5vlx330 in RPS3K board.
\end{abstract}

Keywords : Lifting based IWT, Wavelet transform, Hardware architecture

\section{I. 서론}

최근 이동전화 단말기를 중심으로 휴대용 디지 털 기기의 큰 발전이 이루어졌다. 이러한 발전에 더 불어 휴대용 기기를 사용하는 사용자 역시 동영상 이나 비디오 서비스와 같은 대용량 정보와 이를 적 절하게 제공할 수 있는 질적으로 향상된 서비스를 요구하고 있다. 이와 같은 사용자의 요구에 맞춰 대 용량 데이터를 효율적으로 처리하기 위해 영상 압 축에 관련된 여러 가지 표준이 제정되어 있다. 이러 한 표준으로는 광범위하게 사용되고 있는 JPEG (Joint Photographic Experts Group), MPEG (Moving Picture Experts Group) 및 H.26x가 있 다.

\footnotetext{
* 교신저자(Corresponding Author)

논문접수 : 2012.01.27., 수정일 : 2012.02.25.,

채택확정 : 2012.04.09.

김석준, 장영조 : 한국기술교육대학교
}

JPEG과 MPEG은 DCT (Discrete Cosine Transform)를 기반으로 하고 있다. 그러나 DCT는 블록 효과라는 극복할 수 없는 단점을 갖고 있다. 이를 보완하기 위한 많은 연구가 활발히 진행되고 있다.

이중 가장 주목받고 있는 기술은 웨이블릿 (wavelet) 기반의 영상처리 기술로써 DWT ( Discrete Wavelet Transform)는 블록 효과를 제거 할 수 있을 뿐 아니라 전체 영상을 대상으로 인간 의 시각에 따른 처리가 가능하다. 이러한 특성 때문 에 DWT는 DCT를 대신하여 JPEG2000의 주파수 변환 기술로 지정되었다 [1].

DWT에 대한 전통적인 구현 방식은 FIR (Finite Impulse Response) 필터 뱅크(filter bank)를 사용 하거나 컨볼루션 기반의 방법이 사용된다. 이러한 구현 방식은 영상처리에 요구되는 고속 처리나 저 전력의 하드웨어 구현을 위한 면적 면에서 적합하 지 않은 방식이다.

Knowles를 시작으로 Daubechies와 Sweldens 등이 삼각 행렬과 밴드 행렬 곱셈을 사용하여 푸리 
에 변환(Fourier Transform)에 의존하지 않는 리프 팅(lifting) 기반의 웨이블릿 변환을 제안하였으며 [2-4], 이를 바탕으로 VLSI 하드웨어 구현을 위한 연구가 활발하게 진행되고 있다 [5-8]. 이러한 리 프팅 기반의 구현은 FIR 필터 뱅크나 컨볼루션을 기반으로 하는 구현 방식보다 우수한 성능 향상을 보였으며, 실시간 처리를 해야 하는 모바일 분야에 도 적용 가능하다. 그러나 하드웨어 구현을 위하여 서는 비교적 큰 메모리와 큰 처리 시간을 요구한다.

본 논문에서는 기존에 제안된 1 차원 IWT (Integer Wavelet Transform) [9]를 사용하여 2차 원 변환기를 설계한다. 이 1차원 IWT는 곱셈기를 시프트 레지스터로 대체하여 $(5,3)$ 필터를 설계할 수 있으며 정수 연산을 사용하기 때문에 구조가 비 교적 간단하고 규칙적이며 무손실 변환의 특성을 가진다.

1 차원 변환기를 2 차원 변환에 적용하기 위해서 는 행 방향으로 1 차원 변환을 적용하고, 그 결과 값 에 대해 열 방향으로 두 번째 1 차원 변환을 적용한 다. 그러나 1 차원 변환기를 구조 변경없이 2 차원 변환에 적용하면, $\mathrm{NxM}$ 크기의 영상은 세로 방향의 변환을 위해 $\mathrm{NxM}$ 크기의 메모리가 필요하고 실행 시간은 $1.5 \mathrm{xNxM}$ 개 정도의 클록이 필요하다. 기존 에 제안된 2차원 변환기는 샘플을 순차적으로 입력 받아 1 차원 변환이 완료된 값을 메모리에 저장하기 때문에 영상의 크기가 증가하면 이에 필요한 메모 리의 크기도 증가한다 [10].

본 논문에서 제안하는 변환기는 기존의 1 차원 변환기의 구조는 유지하면서 N/2 크기의 메모리를 사용하여 행과 열 방향 연산을 동시에 수행할 수 있게 한다. 그 결과 $2 \mathrm{xN}$ 크기의 메모리를 사용하고 실행시간은 $\mathrm{NxM} / 4$ 개 정도로 감소된 클록 수가 필 요하게 된다. 제안한 변환기는 입력 영상의 크기와 상관없이 입력, 덧셈기 그리고 시프트 레지스터의 개수가 2 배 증가하지만, 영상의 열 개수만큼의 메모 리를 사용하고 1 차원 변환 값을 저장하지 않고 연 산에 필요한 계수만을 저장하기 때문에 영상의 전 체 크기에 영향을 받지 않는다. 이를 통해 실행 클 록 수와 메모리 사용량은 기존 변환기에 비해 약 2 배 정도 감소한다.

제안하는 변환기는 Verilog HDL로 설계하고 Xilinx사의 xc5vlx330 FPGA에 구현하여 그 동작 을 확인하였다. 실험에 사용된 영상은 8 비트의 $15 \times 15$ 크기인 정지 영상과 48 프레임(frame)으로 구성된 $\mathrm{CIF}$ (Common Intermediate Format) 동영 상이다.
2장에서는 제안하는 변환기의 구조에 대한 설계 와 구현 및 검증에 대해 설명한다. 3 장에서는 결론 과 향후 연구 과제를 제시한다.

\section{II. 본 론}

\section{1. 제안하는 2 차원 IWT 변환기의 구조}

그림 1 은 제안하는 순방향 2 차원 IWT 변환기의 블록 다이어그램이다. 제안하는 변환기는 두 개의 행 방향 처리기(Row Processor, RP)와 두 개의 열 방향 처리기(Column Processor, CP)로 구성된다.

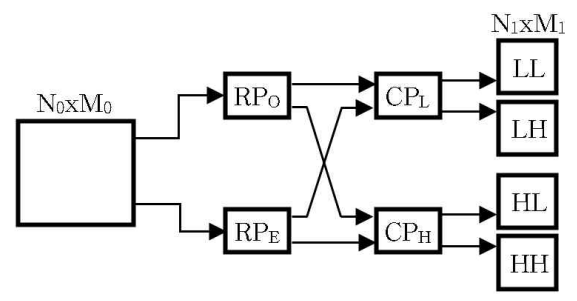

그림 1. 제안하는 구조

Fig. 1. Proposed architecture

원본 영상을 $\mathrm{N}_{0} \mathrm{XM}_{0}$ (열X행), 2 차원 변환이 완료 된 영상을 $\mathrm{N}_{1} \mathrm{XM}_{1}$ 이라 할 때, 2 차원 영상을 처리하 는 방법은 다음과 같다. 두 개의 행 방향 처리기 $\left(\mathrm{RP}_{\mathrm{O}}\right.$ 와 $\left.\mathrm{RP}_{\mathrm{E}}\right)$ 는 네 개의 값 $\left(\mathrm{L}_{\mathrm{odd}}, \mathrm{H}_{\mathrm{odd}}\right.$ 와 $\mathrm{L}_{\mathrm{even}}$, $\left.\mathrm{H}_{\mathrm{even}}\right)$ 을 출력한다. $\mathrm{CP}_{\mathrm{L}}$ 은 $\mathrm{L}_{\mathrm{odd}}$ 와 $\mathrm{L}_{\mathrm{even}}$ 을 사용하여 LL과 $\mathrm{LH}$ 를 출력한다. $\mathrm{CP}_{\mathrm{H}}$ 는 $\mathrm{H}_{\mathrm{odd}}$ 와 $\mathrm{H}_{\mathrm{even}}$ 을 사용 하여 HL과 $\mathrm{HH}$ 를 출력한다.

이러한 구조를 사용하면 $\mathrm{RP}$ 에서 처리한 값이 출 력됨과 동시에 $\mathrm{CP}$ 의 입력으로 사용될 수 있기 때문 에 기존 변환기를 사용하여 2 차원 변환을 할 때에 비해 변환 시간을 약 2 배 단축할 수 있게 된다.

\section{1 행 방향 처리기}

영상에 행 방향으로 1 차원 변환을 적용하기 위 해 각 $\mathrm{H}$ (high) 및 $\mathrm{L}(\mathrm{low})$ 패스 웨이블릿 계수 $d_{1}(i, j)$ 와 $a_{1}(i, j)$ 는 식 (1)을 사용하여 구한다.

$$
\begin{aligned}
& d_{1}(i, j)=a_{0}^{\text {odd }}(i, j)-\frac{1}{2}\left(a_{0}^{\text {even }}(i-1, j)+a_{0}^{\text {even }}(i, j)\right) \\
& a_{1}(i, j)=a_{0}^{\text {even }}(i-1, j)+\frac{1}{4}\left(d_{1}(i, j)+d_{1}(i-1, j)\right)
\end{aligned}
$$

$i, j$ 는 열과 행을 의미한다. $i=0,1,2, \ldots N / 2-1$ 이고, $j=0,1,2, \ldots, M-1$ 이다. $a_{0}^{\text {odd }}$ 와 $a_{0}^{\text {even }}$ 은 입력을 
홀수와 짝수 샘플로 나누는 것을 의미한다.

식 (1)을 덧셈기와 시프트 레지스터를 조합하여 그림 2 와 같이 구성할 수 있다. 이 구조는 $\mathrm{Al}-$ Sulaifanie 등 [9]이 제안한 변환기와 동일하지만 제 어 신호를 제거하고 $\mathrm{L}$ 과 $\mathrm{H}$ 처리기를 각각 구성하고, 두 개의 행 방향 처리기를 사용한다.

$\mathrm{reg}$ 는 $\mathrm{D}-\mathrm{F} / \mathrm{F}$ 을 사용하여 이전 입력을 저장하는 역할을 하며, 입력된 신호가 지연 없이 출력 신호로 반영되는 래치(latch)를 사용하여 행 방향 변환을 한 클록에 수행할 수 있도록 한다. in 1 과 in2는 $\mathrm{M}$ 번째 행의 홀수와 짝수 번째 입력 샘플이다. out1과 out2 는 행 방향 변환이 완료된 계수 값으로 각각 $\mathrm{L}\left(a_{1}\right)$ 과 $\mathrm{H}\left(d_{1}\right)$ 이다.



그림 2. 행 방향 처리기

Fig. 2. Row processor

\section{2 열 방향 처리기}

열 방향 변환은 행 방향 변환과 유사하게 이전 에 변환된 계수가 필요하다. 이것은 식 (2)와 같이 표 현할 수 있다.

$$
\begin{aligned}
& d_{2}(i, j)=a_{1}^{\text {odd }}(i, j)-\frac{1}{2}\left(a_{1}^{\text {even }}(i, j-1)+a_{1}^{\text {even }}(i, j)\right) \\
& a_{2}(i, j)=a_{1}^{\text {even }}(i, j-1)+\frac{1}{4}\left(d_{2}(i, j)+d_{2}(i, j-1)\right)
\end{aligned}
$$

식 (2)의 $i, j$ 는 각각 열과 행을 의미한다. $i=0,1,2, \ldots, N / 2-1$ 이고, $\quad j=0,1,2, \ldots, M / 2-1$ 이 다. 그리고 $a_{1}^{o d d}, a_{1}^{e v e n}$ 은 행 방향 처리기에서 출력된 계수를 홀수와 짝수로 나누는 것을 의미한다.

열 방향 처리기의 구조는 행 방향 처리기와 유 사하다. 그러나 제안하는 변환기의 입력은 행 방향으 로 입력되고, 행 방향 변환이 완료된 직후 연속으로 열 방향 변환이 진행된다. 이로 인해 열 방향 변환기 는 행 방향 변환기에서 출력된 계수를 저장하는 메모 리가 필요하다. 이러한 계수를 저장하기 위해서는 $\mathrm{N}_{0} / 2$ 크기의 메모리 두 개가 필요하다.

그림 3 은 열 방향 처리기의 구조를 보여준다.
MEMO은 행 방향 변환이 완료된 짝수 행의 $\mathrm{L}$ 또는 $\mathrm{H}$ 를 저장한다. MEM1은 열 방향 변환이 완료된 $\mathrm{LH}$ 또는 $\mathrm{HH}$ 를 저장한다. 이렇게 저장된 값들은 다음 행 변환에 사용된다. in1과 in2는 행 방향 변환이 완료 된 $\mathrm{L}$ 또는 $\mathrm{H}$ 이다. out1과 out2는 $\mathrm{L}$ 변환일 경우 $\mathrm{LL}$ 과 $\mathrm{LH}$ 이고, $\mathrm{H}$ 변환일 경우 $\mathrm{HL}$ 과 $\mathrm{HH}$ 이다.

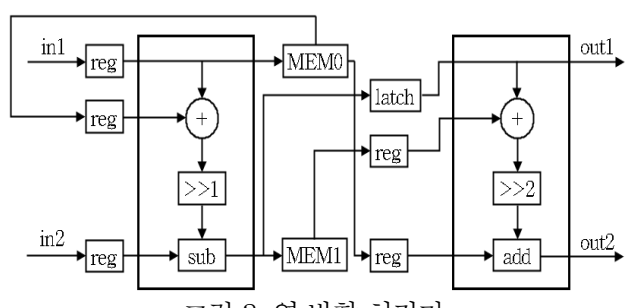

그림 3. 열 방향 처리기

Fig. 3. Column processor

\section{3 제어기}

그림 4 는 2 차원 IWT 변환기의 제어기의 블록도 이다. 행 방향 처리기는 특별한 제어 신호 없이 동작 가능하다. 그러나 열 방향 처리기는 이전 값을 저장 하는 메모리를 포함하므로 제어 신호가 필요하다.

각 신호의 역할은 다음과 같다. start 신호는 2 차원 변환의 시작을 알리는 신호이다. done 신호는 2 차원 변환기와 기타 모듈을 제어하는 외부 제어 모 듈에서 출력되는 신호를 입력받는다. 이 신호는 양 방향 2 차원 변환이 완료되었음을 의미하며, 이 신호 로 인해 출력 신호인 rd_en, rd_addr, wr_en 및 wr_addr 신호를 초기화한다. rd_en과 rd_addr은 메 모리 읽기 신호와 주소로 열 방향 처리기의 연산에 적절한 값을 제공하기 위해 사용된다. wr_en과 $\mathrm{wr}$ addr은 그림 3 의 중간 출력 값을 메모리에 저장 하기 위한 신호로 사용한다.

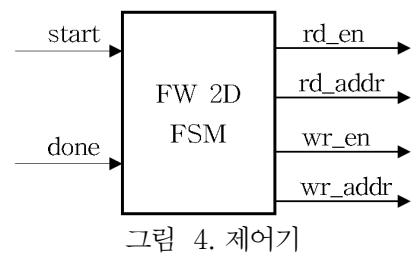

Fig. 4. Controller

\section{2. 구현 및 동작실험}

제안한 2차원 변환기의 구조를 Verilog HDL로 설계하고 $\mathrm{FPGA}$ 에 구현하여 8 비트의 $15 \times 15$ 의 픽 
셀 크기로 된 정지영상과 $\mathrm{CIF}$ 동영상을 사용하여 동작을 검증한다. Xlinx의 xc5vlx330 FPGA가 탑 재된 Huins 사의 RPS3K 장비에서 CIF 영상 48 프 레임(약 1.5 초)을 실시간으로 변환하고 동작하는 실 험 결과를 설명한다.

\section{$2.115 \times 15$ 영상}

그림 5 는 제안하는 구조를 사용하여 변환할 3장 의 영상을 보여준다. 이 영상의 RGB 색상 중 8 비트 의 R 성분을 사용한다. 또한, 3 장의 영상들을 사용하 여 연속으로 변환할 수 있음을 시뮬레이션을 통하여 확인한다.
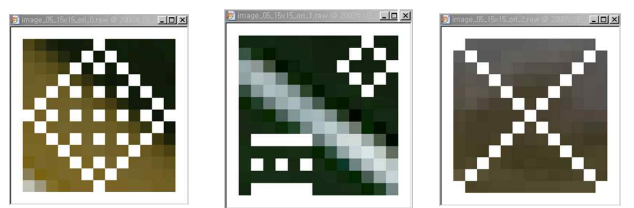

그림 5. 원본 입력 영상

Fig. 5. Original input images

그림 6 은 $\mathrm{iSim}$ 을 사용한 시뮬레이션 파형이다. 파형에서 2 차원 변환기는 2 개의 클록 지연이 있고, 한 개의 행을 변환하려면 10 개의 클록이 필요하다. 두 개의 행을 동시에 변환하므로 $15 \times 15$ 영상은 총
8번의 행 변환이 필요하다. 따라서 한 장의 영상을 변환하는 데 필요한 클록 수는 82 개이고 3 장의 영상 을 연속으로 변환하면 총 242 개의 클록이 필요하다. 이때 메모리는 40x10 비트가 필요하다.

그림 7은 RPS3K를 사용하여 검증한 결과이다. 그림 7 의 윗 줄 영상들은 원본 입력 영상들이고, 중 간 줄의 영상들은 양 방향 변환이 완료된 영상들이 다. 아래 줄 영상들은 각 원본 영상과 변환이 완료된 영상의 차이를 보여주고 있는데 원본 영상과 변환된 영상의 차이가 없음을 알 수 있다.

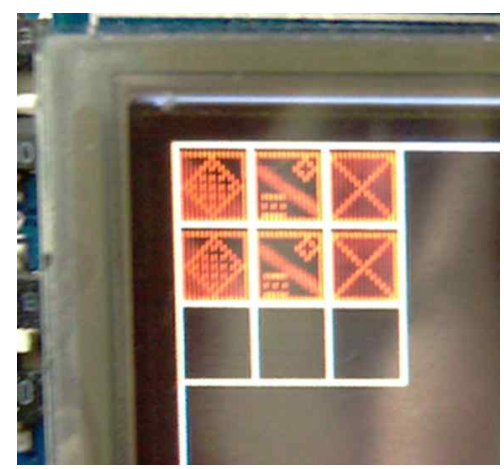

그림 $7.15 \times 153$ 개 영상의 실험 결과

Fig. 7. Experimental result for three $15 \times 15$ images

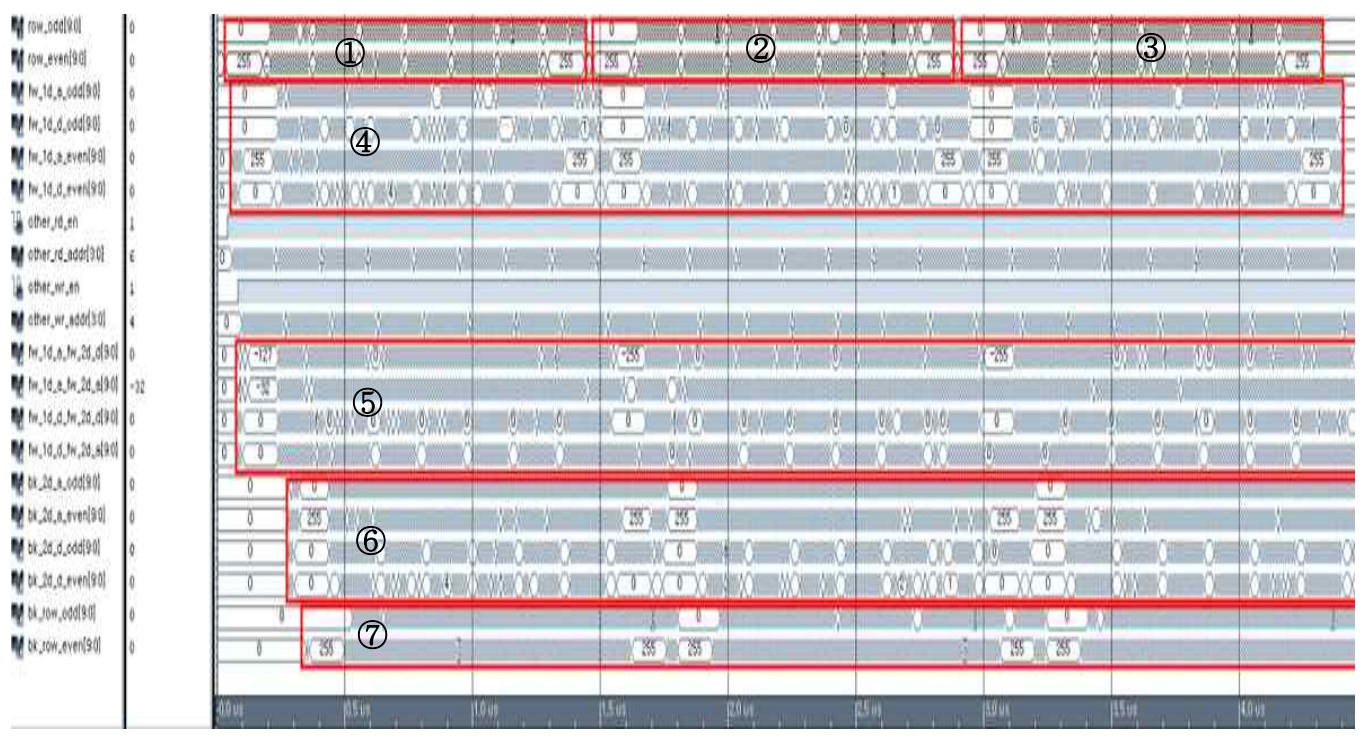

(1) (3) : 3 장의 연속된 입력 영상

(4) : 순방향 1 차원(행) 변환 (5) : 순방향 2 차원(열) 변환

(6) : 역방향 2 차원(열) 변환 (7): 역방향 1 차원(행) 변환

그림 6. 시뮬레이션 파형

Fig. 6. Simulation Wave 


\section{$2.2352 \times 240$ (CIF) 영상}

$4: 4: 4$ 로 샘플링 된 $\mathrm{YCbCr}$ 의 각 성분이 8 비트 인 $\mathrm{CIF}$ 영상 48 프레임에 대한 IWT 변환을 위해 $\mathrm{RPS} 3 \mathrm{~K}$ 장비의 외부 SDRAM에 영상을 저장한다. 그 림 8은 $\mathrm{CIF}$ 영상을 변환하기 위한 전체 블록도이다. 외부 $\mathrm{SDRAM}$ 에 저장된 $\mathrm{YCbCr}$ 영상을 한 프레임씩 $\mathrm{FPGA}$ 의 내부 메모리에 저장하고, 저장된 영상을 제 안하는 2 차원 변환기의 입력으로 사용한다. 순방향 변환기의 출력은 역방향 변환기의 입력으로 사용하 고, 복원된 영상은 메모리와 $\mathrm{RGB}$ 변환기를 거쳐 TFT-LCD로 출력한다.

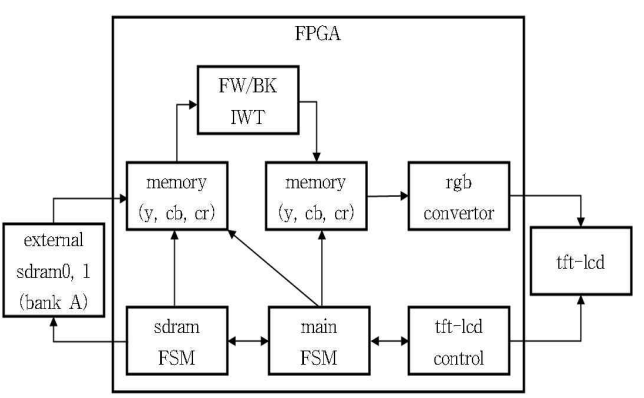

그림 8. CIF 영상을 처리하기 위한 블록도

Fig. 8. Block diagram to process CIF images

그림 9 (a)는 CIF 동영상의 순방향 2차원 변환 이 완료된 동영상을 보여주며, 그림 9 (b)는 역방향 2 차원 변환이 완료된 동영상을 보여준다. 1 프레임의 $\mathrm{CIF}$ 영상을 변환하기 위해서는 21,540 개의 클록이 필요하고, $712 \times 10$ 비트의 메모리가 필요하다. 실험 의 동작 확인을 통하여 제안하는 변환기는 실시간 응 용에 사용할 수 있고, 입력 영상의 손실 없이 복원되 고 있음을 알 수 있다.

\section{3. 성능분석 및 비교}

표 1은 8비트 256x256 크기의 영상에 대해, 기 존의 2차원 변환기를 사용한 경우(1) [10], $\mathrm{Al}-$ Sulaifanie 등이 제안한 1 차원 변환기를 사용하 여 2차원 변환기를 사용한 경우(2) [9], 그리고 본 논문에서 제안하는 변환기를 사용한 경우(3)의 하 드웨어 사용과 실행 클록 수에 대한 성능을 비교한 것이다.

제안하는 구조는 기존의 변환기(1))보다 약 두 배의 덧셈기와 시프트 레지스터를 사용한다. 그러나 메모리 사용량은 반으로 감소하여 하드웨어의 구현 에 필요한 면적은 유사한 비율을 유지함에 비하여
변환에 필요한 실행 클록수가 반으로 감소하여 동 작속도의 성능이 향상됨을 알 수 있다.

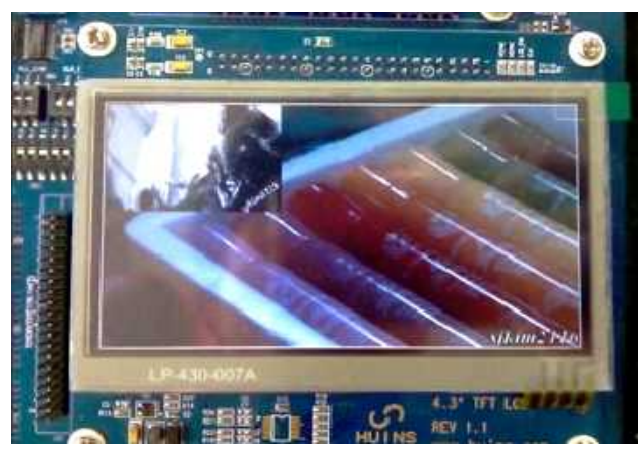

(a) 순방향 2 차원 변환

(a) Forward 2D transform

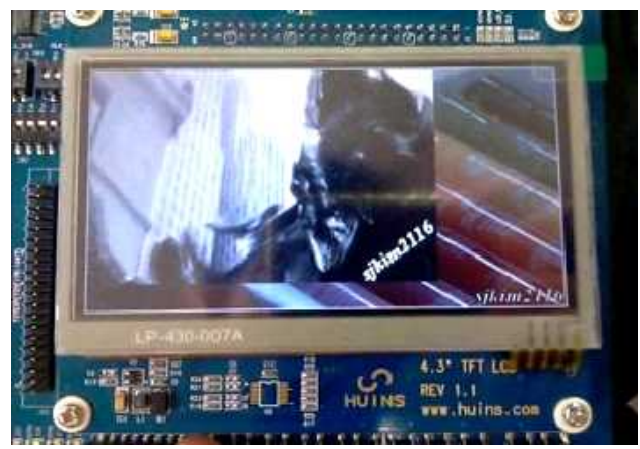

(b) 역방향 2 차원 변환

(b) Backward 2D transform

그림 9. $\mathrm{CIF}$ 영상의 실험 결과

Fig. 9. Experimental result for CIF images

표 1. 성능 비교

Table 1. Performance Comparisons

\begin{tabular}{|c|c|c|c|}
\hline & 1 & 2 & (3) \\
\hline 덧 셈기 & 8 & 12 & 16 \\
\hline 시프트 레지스터 & 4 & 6 & 8 \\
\hline 레지스터 & 18 & 18 & 22 \\
\hline 메모리 & 1,024 & 66,560 & 520 \\
\hline 실행 클록 수 & 33,290 & 50,184 & 16,772 \\
\hline
\end{tabular}

표 2는 제안하는 변환기를 사용하여 다양한 크 기의 동영상에 실시간 변환을 적용할 수 있음을 확 인한 것으로 각 영상의 크기에 따른 실행 클록과 메모리 사용량을 보여준다. $4: 4: 4$ 로 샘플링된 $\mathrm{YCbCr}$ 이 각 8 비트인 $\mathrm{CIF}$ 동영상 30 프레임을 변 환할 때 사용된 메인 클록의 동작 주파수가 $100 \mathrm{MHz}$ 이라면 약 $6.5 \mathrm{~ms}$ 정도의 변환 시간이 소요 
된다. $\mathrm{HD}$ 급 $1,920 \times 1,080$ 의 영상 크기인 동영상에 대하여 30 프레임을 변환하면 약 $156 \mathrm{~ms}$ 정도가 필 요하고, 메모리 사용량은 영상 열 크기 $(1,080)$ 의 두 배 정도를 사용한다.

표 2. 동영상 크기에 대한 성능

Table 2. Performance for image size

\begin{tabular}{|c|c|c|c|c|}
\hline \multicolumn{2}{|c|}{ 영상크기 } & \multirow{2}{*}{$\begin{array}{l}\text { 클록 } \\
\text { (30장) }\end{array}$} & \multirow{2}{*}{$\begin{array}{c}\text { 시간 }(\mathrm{ms}) \\
@ 100 \mathrm{MHz}\end{array}$} & \multirow{2}{*}{$\begin{array}{c}\text { 메모리 } \\
\text { (10bit) }\end{array}$} \\
\hline 열 & 행 & & & \\
\hline 1,920 & 1,080 & $15,613,320$ & 156.1 & 3,848 \\
\hline 1,280 & 720 & $6,952,920$ & 69.5 & 2,568 \\
\hline 720 & 576 & $3,138,600$ & 31.4 & 1,448 \\
\hline 704 & 576 & $3,069,240$ & 30.7 & 1,416 \\
\hline 640 & 480 & $2,328,120$ & 23.3 & 1,288 \\
\hline 352 & 240 & 646,200 & 6.5 & 712 \\
\hline 176 & 120 & 164,760 & 1.6 & 360 \\
\hline
\end{tabular}

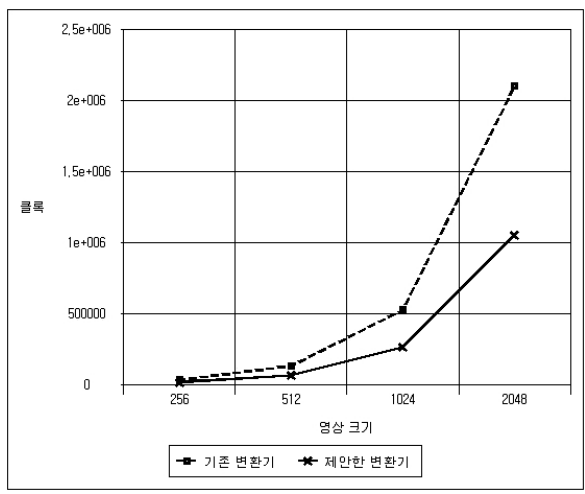

(a) 실행 클록 수

(a) Number of execution clock

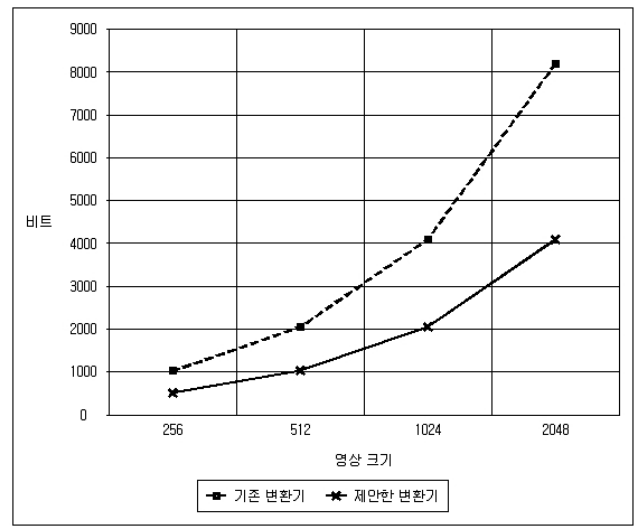

(b) 메모리 사용량

(b) Memory size

그림 $10 . \mathrm{NxN}$ 영상에 대한 비교

Fig. 10. Comparisons for $\mathrm{NxN}$ image
그림 10은 행과 열의 크기가 같은 $\mathrm{NxN}$ 영상에 대해 기존 변환기(1)와 제안하는 변환기의 실행 클 록과 메모리 사용량에 대한 비교를 보여준다. 제안 하는 변환기의 실행 클록과 메모리 사용량은 영상 크기와 상관없이 기존 변환기보다 두 배의 성능이 향상됨을 예측할 수 있으며, 이를 통해 제안하는 구 조를 사용하여 다양한 크기의 영상을 실시간 2 차원 변환이 가능함을 알 수 있다.

\section{III. 결론}

본 논문에서는 덧셈기와 시프트 레지스터로 구 성된 2차원 IWT 변환기를 설계하였다. 설계된 2차 원 변환기는 실시간 영상 압축과 복원에 사용될 수 있다. 또한 주파수 변환을 사용하는 워터마킹 기법 이나 추가적인 모듈과 함께 JPEG2000의 구현에 적용할 수 있다. 실시간 처리와 대용량 데이터를 요 구하는 감시 및 보안과 관련된 CCTV와 모바일 동 영상 처리 분야에서도 사용될 수 있다.

제안하는 구조를 구현하기 위해 Verilog HDL로 설계하고 Xilinx의 iSim을 사용하여 동작을 시뮬레 이션하였다. Xilinx의 xc5vlx330을 탑재하고 있는 Huins사의 RPS3K 장비를 사용하여 실시간 동작을 검증하였다. 2 개의 행을 동시에 처리하여 1 차원 변 환 값이 출력된 직후 2 차원 변환이 이루어지고 각 영상은 연속으로 입력될 수 있도록 설계하였다.

$\mathrm{FPGA}$ 의 동작 주파수를 $100 \mathrm{MHz}$ 로 하고 $\mathrm{YCbCr}$ 이 4:4:4로 샘플링된 CIF 30 프레임을 변환할 때 순방향 2 차원 변환에는 총 646,200 개의 클록이 필 요하며, 이를 시간으로 환산하면 약 $6.5 \mathrm{~ms}$ 정도이 다. 연산에 필요한 값을 저장하기 위한 메모리는 $712 \times 10$ 비트가 필요하다. 기존에 제안된 2차원 변 환기와 비교하면 영상의 크기와 상관없이 입력, 덧 셈기 그리고 시프트 레지스터의 개수는 두 배 증가 하지만, 실행 클록과 메모리 사용량은 반으로 감소 한다. 제안하는 구조의 IWT를 적용하면 모바일 동 영상과 같은 실시간 영상 처리가 충분히 가능할 것 으로 예측된다.

본 논문에서 제안하는 구조는 고정 크기의 영상 만을 변환할 수 있는 구조이다. 향후 다양한 크기의 영상에 적용할 수 있는 변환기를 설계하여, 여러 크 기의 영상을 추가적인 구조의 변경없이 사용할 수 있는 변환기의 연구를 진행하고자 한다. 또한, 제안 하는 구조는 유지하면서 $(5,3)$ 필터 이외의 다양한 필터도 지원하는 연구를 진행할 것이다. 


\section{참 고 문 헌}

[1] M. Boliek, "JPEG 2000 Part I Final Draft International Standard," ISO/IEC JTC1/SC29 WG1, 2000.

[2] G. Knowles, "VLSI Architecture for the Discrete Wavelet Transform," IEEE Electronic Letters, Vol. 26, No. 15, pp.1184-1185, 1990.

[3] I. Daubechies, W. Sweldens, "Factoring wavelet transforms into lifting steps," Preprint, Bell Lab. 1996.

[4] A.R. Calderbank, I. Daubechies, W. Sweldens, B. Yeo, "Wavelet transforms that map integers to integers," Technical Reports, Depart. of Mathematics, Princeton University, 1996.

[5] C. Hunag, P. Tseng, L. Chen, "Efficient VLSI architectures of lifting-based discrete wavelet transform by systematic design method," Proceedings on IEEE International Symposium Circuits and Systems, Vol. 5, pp.565-568. 2002.

[6] B. Wu, C. Lin, "A high-performance and memory efficient pipeline architecture for the $5 / 3$ and $9 / 7$ discrete wavelet transform of JPEG2000 codec," IEEE Transactions on Circuits and Systems for Video Technology, Vol. 15, No. 12, pp.1615-628, 2005.

[7] T. Acharya, "A Survey on Lifting-based Discrete Wavelet Transform Architectures," Journal of VLSI Signal Process, Vol. 42, No. 3, pp.312-339, 2006.

[8] B. Harish, "FPGA Implementation of Multiplierless 5/3 Legal Discrete Wavelet Transform Using Lifting Approach," Proceedings on the International Conference \& Workshop on Emerging Trends in Technology, pp.1066-1071, 2011.

[9] A.K. Al-Sulaifanie, A. Ahmadi, M. Zwolinski, "Very large scale integration architecture for integer wavelet transform," IET Computers and Digital Techniques, Vol. 4, No. 6, pp.471-483, 2009.

[10] K. Andra, "A VLSI Architecture for

Lifting-Based Forward and Inverse Wavelet Transform," IEEE Transactions on Signal Processing, Vol. 50, No. 4, pp.966-977, 2002.

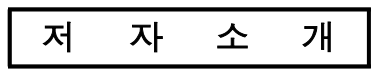

\section{김 석 준}

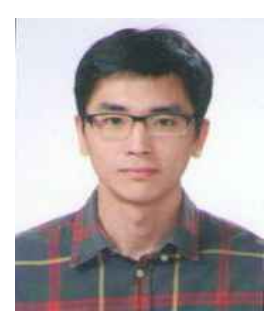

2008년 한국기술교육대 학교 정보기술공학부 전 자공학 학사.

2012년 한국기술교육대 학교 전기전자통신공학과 전자공학 전공 석사.

관심 분야 : 영상 압축

Email : sjkim2116@gmail.com

장 영 조



1979년 경북대학교 전자 공학과 학사.

1982년 동 대학원 석사. 1992년 한국과학기술원 전기및전자공학과 박사. 1981년 1993년 전자통 신연구원.

1993년 현재 한국기술교육대학교 전기전 자통신공학부 교수.

관심분야 : 영상처리 $\mathrm{SoC}$ 설계, 임베디드 $\mathrm{SoC}$ 설계

Email:yjjang@kut.ac.kr 